ПРИМЕНЕНИЕ КОМПЬЮТЕРНОГО ТЕСТИРОВАНИЯ ДЛЯ ОЦЕНКИ УЧЕБНЫХ ДОСТИЖЕНИЙ СТУДЕНТОВ ПО БИОЛОГИЧЕСКОЙ ХИМИИ В УЧРЕЖДЕНИЯХ ВЫСШЕГО МЕДИЦИНСКОГО ОБРАЗОВАНИЯ

Петушок Н. Э. (kbh@grsmu.by), Леднева И. О., Лелевич В. В., Курбат М. Н. УО «Гродненский государственный медицинский университет», Гродно, Беларусь

\footnotetext{
Введение. Оиенка знаний обучающчихся является одной из ключевых задач любой образовательной систеMbl.

Цель исследования. Выявление значимости тестирования в комплексной системе средств оценки знаний обучаюшихся.

Материал и методы. Статистический анализ взаимосвязи результатов компьютерного тестирования, экзаменационной оценки и среднегодового балла.

Результаты. Выявлена положительная корреляциионная связь между всеми парами сравниваемых показателей. У студентов лечебного факультета высокая теснота связи отмечена в парах показателей среднегодовой балл $\leftrightarrow$ экзаменационная оценка и тестирование ↔ экзаменационная оценка. У студентов факультета иностранных учашихся тенденции взаимозависимости показателей сходны, теснота связи менее выражена.

Выводы. Компьютерное тестирование должно использоваться в совокупности с другими средствами контроля.

Ключевые слова: компьютерное тестирование, среднегодовой балл, экзаменационная оценка, коэффициент корреляциии.
}

Контроль и оценка знаний обучающихся одна из ключевых задач любой образовательной системы. Педагогические измерения в условиях применения государственных образовательных стандартов включаются в систему мониторинга предметных достижений с целью анализа функционирования педагогической системы и повышения эффективности управления ею. Опыт высших учебных заведений стран СНГ и белорусских вузов свидетельствует о том, что возможны разные модификации систем и средств диагностирования. Российские ведущие научно-педагогические центры создали примерные фонды оценочных средств. В Беларуси широкое распространение получили тестовые формы диагностики, апробируются комплексные квалификационные задания, обобщенные задачи [1].

Согласно инновационной модели развития образования, в системе контроля знаний должны присутствовать составляющие, которые позволяют оценить объём знаний, практические умения и навыки, а также мышление и речь обучающегося. Методом исследования уровня знаний, умений, навыков, способностей и других личностных качеств является такая форма контроля, как тест. Практическая цель использования компьютеров для тестирования уровня знаний заключается в достижении высоких показателей скорости, точности, непредвзятости в оценке и уменьшении трудоёмкости данного процесса. От других методов педагогической диагностики тесты отличаются тем, что предполагают стандартизованную процедуру сбора, обработки и интерпретации данных, позволяют проверить знания обучающихся по широкому спектру вопросов изучаемой дисциплины, существенно сокращают затраты времени на проверку результата, исключают субъективизм преподавателя как в процессе контроля, так и в процессе оценки [2].

\section{Материал и методы}

Обобщен опыт применения тестирования, проведен анализ взаимосвязей результата итогового компьютерного тестирования, экзаменационной оценки и среднегодового балла 1273 студентов УО «Гродненский государственный медицинский университет» (ГрГМУ) лечебного факультета и факультета иностранных учащихся (русский язык обучения) по дисциплине «Биологическая химия» с 2014 по 2016 г. Данные обработаны методами параметрической статистики с применением коэффициента Стьюдента, представлены в виде среднего значения выборки и ошибки среднего $(\mathrm{M} \pm \mathrm{m})$. Рассчитаны коэффициенты корреляции Спирмена [3].

\section{Результаты и обсуждение}

На кафедре биологической химии ГрГМУ тесты в качестве инструмента педагогической диагностики применяются с 2001 г. В течение этого времени велась постоянная работа по совершенствованию их содержания. Оно должно соответствовать современному состоянию науки, целям тестирования, содержанию учебной дисциплины. Кроме того, тесты должны быть корректными, а формулировки вопросов, ответов и дистракторов (отвлекающих ответов) краткими и однозначными [4]. При разработке тестов учитывались общие требования тестологии и обобщенный опыт создания образовательных тестов в ГрГМУ. Тестирование проводится с помощью компьютерной тестирующей среды Web Test Servis, разработанной сотрудниками университета.

После апробации нескольких вариантов тестов мы остановились на компьютерных аттестационных тестах закрытого типа с четырьмя вариантами ответов $[5,6]$. В них есть задания как одиночного выбора (с единственно правильным ответом), так и с множественным выбором 
(из предложенных вариантов нужно выбрать все правильные). Для ответа на один вопрос студенту даётся 30 секунд. Содержание тестов отражает содержание дисциплины, структурировано по тематическим разделам, включает основные и значимые положения, которые обучающийся должен знать в результате изучения дисциплины. Для усиления обучающей функции тестирования в сборниках тестов приводятся правильные ответы к ним.

Изначально тестирование по биологической химии было только итоговым, проводилось раз в год в конце изучения дисциплины. Это позволяло оценить степень владения базовыми знаниями и стимулировало обучающихся к повторению всего учебного материала. Задания для итогового тестирования включают более 700 тестовых заданий по всем разделам дисциплины. Особое внимание уделено величинам основных лабораторных показателей. Из этого массива каждому студенту методом случайной выборки предлагается 40 тестов.

Впоследствии стали проводить и промежуточные тестирования. Они проходят дважды в семестр перед каждым итоговым занятием. В этом случае тесты включают примерно 100 вопросов по определенному разделу дисциплины. Студенту для ответа предлагается 20 заданий. Введение промежуточного тестового контроля решает ряд задач. Во-первых, периодичность и неизбежность тестирования дисциплинирует, организует и направляет деятельность обучающихся. Во-вторых, студенты получают возможность постепенно адаптироваться к такой форме контроля знаний. Как показывает практика, не все обучающиеся изначально одинаково хорошо приспособлены к проведению контроля методом тестирования. Необходимость вдумчивого чте- ния, быстрого восприятия и анализа информации (особенно с экрана компьютера) представляет собой значительное препятствие для ряда студентов. Адаптируемость обучающихся к проведению тестирований иллюстрируют данные, представленные на рисунке.

Они показывают поступательный рост среднего балла тестирования в течение года. У студентов лечебного факультета результат последнего тестирования выше первого на 10\%. У студентов факультета иностранных учащихся результаты тестирования возрастают на 52\%. Эти данные подчеркивают как обучающую, так и воспитательную функцию тестирования.

Для выявления эффективности тестирования как инструмента оценки знаний студентов (диагностической функции) нами проведено сопоставление оценки, полученной при компьютерном тестировании в конце изучения курса, экзаменационной оценки и среднегодового балла студента. Значения анализируемых показателей представлены в таблице 1.

Как видно из приведённых данных, у студентов лечебного факультета за анализируемый период наблюдается повышение среднегодового балла. Сходная тенденция наблюдается и по итогам компьютерной оценки знаний: результаты за второй и третий год наблюдений выше, чем за первый. Оценка за экзамен практически не изменяется. Сопоставление полученных значений показало, что экзаменационная оценка и результаты компьютерного тестирования достоверно превышают значения среднегодового балла. В 2013/2014 учебном году экзаменационная оценка была выше результатов компьютерного тестирования. Год спустя результаты компьютерного тестирования достоверно превышали экзаменационную оценку.

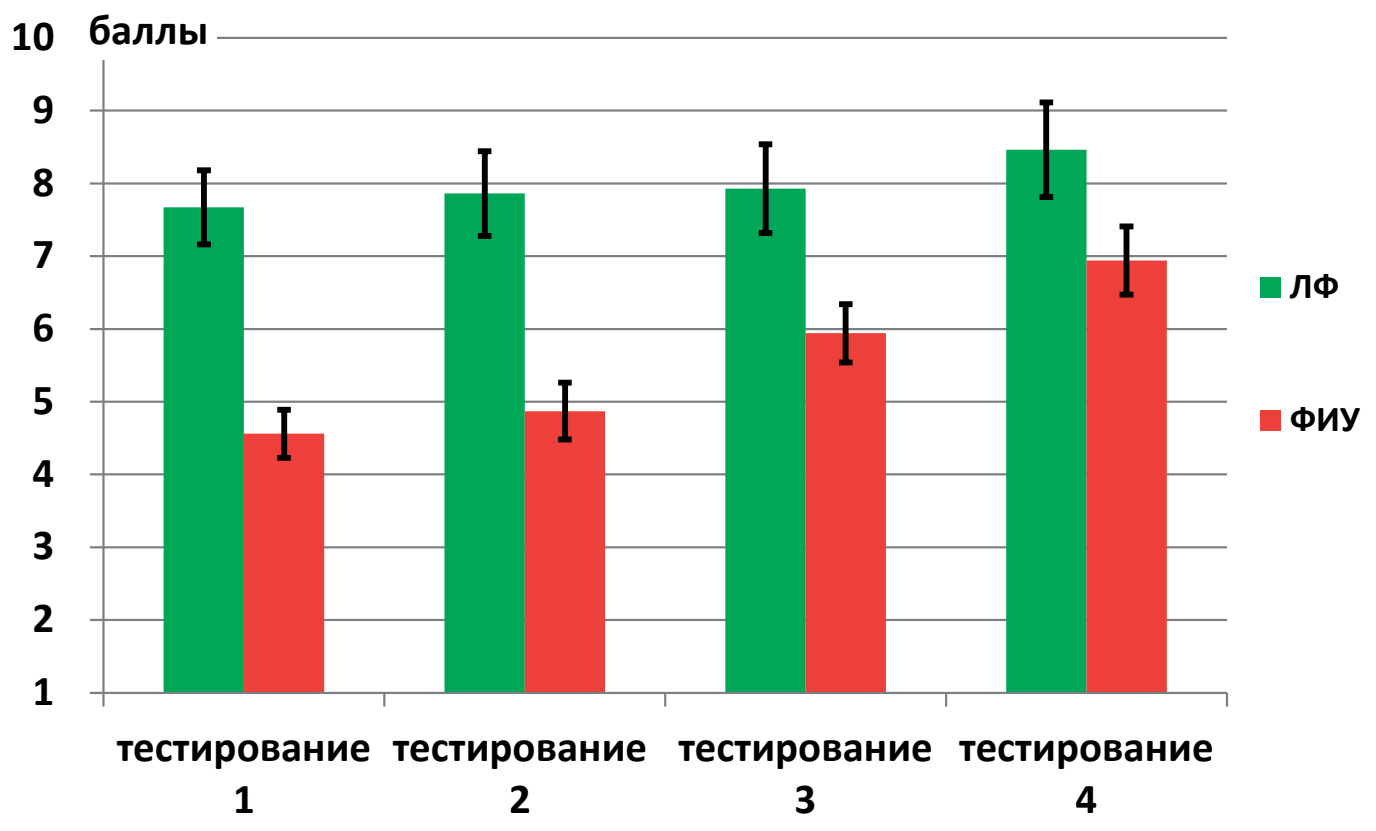

Рисунок. - Средние баллы промежуточных тестирований студентов лечебного факультета и факультета иностранных учащихся в 2015/2016 уч. году 
Tаблица 1. - Результаты успеваемости студентов лечебного факультета и факультета иностранных учащихся по биологической химии $(\mathrm{M} \pm \mathrm{m})$

\begin{tabular}{|c|c|c|c|}
\hline & \multicolumn{3}{|c|}{ Учебный год } \\
\hline & $2013 / 2014$ & $2014 / 2015$ & $2015 / 2016$ \\
\hline \multicolumn{4}{|c|}{ Лечебный факультет } \\
\hline Количество студентов, $\mathrm{n}$ & 418 & 394 & 378 \\
\hline Среднегодовой балл (C) & $5,72 \pm 0,05$ & $5,96 \pm 0,07$ & $6,08 \pm 0,07$ \\
\hline $\begin{array}{l}\text { Результат компьютерного } \\
\text { тестирования (К) }\end{array}$ & $6,16 \pm 0,08^{*}$ & $6,88 \pm 0,10^{*}$ & $6,60 \pm 0,08^{*}$ \\
\hline Экзаменационная оценка (Э) & $6,33 \pm 0,08^{*}, \#$ & $6,32 \pm 0,10^{*}, \#$ & $6,51 \pm 0,11 *$ \\
\hline \multicolumn{4}{|c|}{ Факультет иностранных учащихся } \\
\hline Количество студентов, $n$ & 39 & 26 & 18 \\
\hline Среднегодовой балл (C) & $5,21 \pm 0,14$ & $5,69 \pm 0,11^{\Delta}$ & $5,50 \pm 0,15$ \\
\hline $\begin{array}{l}\text { Результат компьютерного } \\
\text { тестирования (К) }\end{array}$ & $5,19 \pm 0,22$ & $5,65 \pm 0,19^{\Delta}$ & $5,28 \pm 0,24$ \\
\hline Экзаменационная оценка (Э) & $5,61 \pm 0,18^{\#}$ & $5,62 \pm 0,16$ & $5,56 \pm 0,22$ \\
\hline
\end{tabular}

Примечание: статистически значимые различия *- по отномению $к$ среднему баллу, \# - по отношению к тестированию, А - по отношению к предьдущему учебному году

У студентов факультета иностранных учащихся значения среднегодового балла и результаты компьютерного тестирования не демонстрируют единой тенденции. В 2014/2015 учебном году эти показатели достоверно выше, чем в году предшествующем. Однако на экзаменационной оценке это не отразилось: она осталась такой же.

Для более полного анализа взаимосвязей между изучаемыми величинами нами рассчитаны коэффициенты корреляции Спирмена, которые представлены в таблице 2.

Таблица 2. - Коэффициенты корреляции между средним баллом, результатом компьютерного тестирования и экзаменационной оценкой у студентов лечебного факультета и факультета иностранных учащихся

\begin{tabular}{|c|c|c|c|}
\hline Сравниваемые показатели & $2013 / 2014$ & $2014 / 2015$ & $2015 / 2016$ \\
\hline \multicolumn{4}{|c|}{ Лечебный факультет } \\
\hline $\begin{array}{l}\text { Среднегодовой балл ↔ } \\
\text { тестирование }\end{array}$ & $0,66^{*}$ & $0,66^{*}$ & $0,67 *$ \\
\hline $\begin{array}{l}\text { Среднегодовой балл ↔ } \\
\text { экзаменационная оценка }\end{array}$ & $0,82 *$ & $0,80^{*}$ & $0,87^{*}$ \\
\hline $\begin{array}{l}\text { Тестирование ↔ } \\
\text { экзаменационная оценка }\end{array}$ & $0,75^{*}$ & $0,70^{*}$ & $0,72 *$ \\
\hline \multicolumn{4}{|c|}{ Факультет иностранных учащихся } \\
\hline $\begin{array}{l}\text { Среднегодовой балл ↔ } \\
\text { тестирование }\end{array}$ & $0,60^{*}$ & $0,43 *$ & $0,52^{*}$ \\
\hline $\begin{array}{l}\text { Среднегодовой балл ↔ } \\
\text { экзаменационная оценка }\end{array}$ & $0,74 *$ & $0,66^{*}$ & $0,80^{*}$ \\
\hline $\begin{array}{l}\text { Тестирование ↔ } \\
\text { экзаменационная оценка }\end{array}$ & $0,68^{*}$ & $0,59 *$ & $0,72 *$ \\
\hline
\end{tabular}

Примечание: здесь и в таблице $3 *-p<0,05$
Полученные нами результаты демонстрируют прямую корреляционную связь между всеми парами сравниваемых показателей. У студентов лечебного факультета высокая теснота связи отмечена для показателей среднегодовой балл $\leftrightarrow$ экзаменационная оценка и тестирование $\leftrightarrow$ экзаменационная оценка. Умеренная теснота связи выявлена для показателей среднегодовой балл $\leftrightarrow$ тестирование. Значения коэффициентов корреляции в данном случае не превышают 0,67 . Это свидетельствует о том, что студентам проще и легче освоить объем вопросов тестирования, чем регулярно готовиться к текущим занятиям. А возможность получить более высокую оценку на экзамене более высока для тех, кто в течение всего учебного года прилагал больше усилий для получения хорошего среднегодового балла. То есть показатель «среднегодовой балл» более полно оценивает сумму полученных студентами знаний, чем оценка за тестирование. У студентов факультета иностранных учащихся тенденции взаимозависимости обсуждаемых показателей сходны, но между ними отмечена менее выраженная теснота связи.

Наше предположение о причинах меньшей взаимосвязи между результатом тестирования и среднегодовым баллом проверено и по оценке учебных достижений при освоении меньшего объема учебного материала. Для этого рассчитали коэффициенты корреляции между результатом промежуточного компьютерного тестирования и оценкой на итоговом занятии в разных семестрах одного учебного года. Полученные нами результаты представлены в таблице 3 . Они показывают гораздо меньшую тесноту связи между оценками у студентов лечебного факультета. Она изменяется от умеренной до слабой (коэффициент 0,37 в 2015/2016 уч. году). Здесь мы еще более четко видим, что студенты более успешно осваивают вопросы тестирования, так как это требует меньших усилий, чем подготовка к итоговому занятию. Эта тенденция более выражена в осеннем семестре. Степень тесноты связи показателей у студентов факультета иностранных учащихся более стабильна в течение всего учебного года и практически не отличается от результатов, полученных при итоговом контроле. В данном случае студенты, для которых русский язык не является родным, должны прилагать больше усилий для освоения учебного материала и с этой задачей лучше справляются более прилежные, дисциплинированные и старательные студенты, у которых и средняя оценка более высокая [7]. 
Таблица 3. - Коэффициенты корреляции между результатом промежуточного компьютерного тестирования и оценкой на итоговом занятии в разных семестрах у студентов лечебного факультета и факультета иностранных учащихся

\begin{tabular}{|l|c|c|c|c|}
\hline \multirow{2}{*}{ Факультет } & \multicolumn{2}{|c|}{$2014 / 2015$} & \multicolumn{2}{|c|}{$2015 / 2016$} \\
\cline { 2 - 5 } & $\begin{array}{c}\text { осенний } \\
\text { семестр }\end{array}$ & $\begin{array}{c}\text { весенний } \\
\text { семестр }\end{array}$ & $\begin{array}{c}\text { осенний } \\
\text { семестр }\end{array}$ & $\begin{array}{c}\text { весенний } \\
\text { семестр }\end{array}$ \\
\hline $\begin{array}{l}\text { Лечебный } \\
\text { факультет }\end{array}$ & $0,47^{*}$ & $0,55^{*}$ & $0,37^{*}$ & $0,44^{*}$ \\
\hline $\begin{array}{l}\text { Факультет } \\
\text { иностранных } \\
\text { учащихся }\end{array}$ & $0,62^{*}$ & $0,59^{*}$ & $0,66^{*}$ & $0,60^{*}$ \\
\hline
\end{tabular}

няет ещё обучающую и воспитательную функции. На наш взгляд, компьютерное тестирование знаний должно входить в арсенал средств диагностики учебных достижений студентов, использоваться в комплексе с другими формами контроля.

\section{Выводы}

1. Компьютерное тестирование эффективный метод оценки учебных достижений обучающихся при изучении биологической химии.

2. Компьютерное тестирование должно использоваться как один из

Таким образом, проведенный нами анализ свидетельствует о значительной объективности компьютерного тестирования. Она основана на том, что все студенты отвечают на одни и те же вопросы, ответы оцениваются по единой шкале, которая не зависит от субъективного мнения преподавателя. Важнейшие преимущества данной формы педагогической диагностики - экономия времени и возможность проверки знаний по всем разделам дисциплины. Помимо диагностической функции, тестирование выпол-

\section{Литература}

1. Пономарев, Н. Л. Образовательные инновации. Государственная политика и управление : учебное пособие для студентов высших учебных заведений / Н. Л. Пономарёв, Б. М. Смирнов. - Москва : Академия, 2007. - 208 с.

2. Кабанова, Т. А. Тестирование в современном образовании : учебное пособие для вузов / Т. А. Кабанова, В. А. Новиков. - Москва : Высшая школа, 2010. - 381 с.

3. Боровиков, В. П. Statistica. Искусство анализа данных на компьютере / В. П. Боровиков. - Санкт-Петербург : Питер, 2003. - 688 с.

4. Майоров, А. Н. Теория и практика создания тестов для системы образования: как выбирать, создавать и использовать тесты для целей образования / А. Н. Майоров. - Москва : Интеллект-Центр, 2002. $-52 \mathrm{c}$.

5. Эффективность использования компьютерного тестирования при итоговом трехступенчатом контроле знаний студентов / М. Н. Курбат [и др.] // Вышэйшая школа. - 2009. - № 1. - С. 63-65.

6. Применение компьютерного тестирования для оценки учебных достижений студентов по биологической химии / М. Н. Курбат [и др.] // ТехноОбраз 2009: Технологии оценки учебных достижений учащихся и студентов : материалы VII Международной научно-практической конференции, Гродно, 17-18 марта 2009 г. / Учреждение образования «Гродненский государственный университет им. Янки Купалы»; отв. ред. В. П. Тарантей. - Гродно, 2009. - С. 297-301.

7. Компьютерное тестирование как компонент трехступенчатого контроля знаний иностранных учащихся по биологической химии / М. Н. Курбат [и др.] // Перспективы развития высшей школы : материалы II Международной научно-методической конференции, Гродно, 19-20 мая 2016 г. / Учреждение образования "Гродненский государственный аграрный университет ; редкол.: В. К. Пестис [и др.]. - Гродно, 2016. - C. 354-357. инструментов, позволяющих проверить знание эмпирического материала (фактов, референтных величин). Для оценки умения обобщать, применять эти факты нужно использовать другие методы (письменный или устный опрос).

3. Особое значение компьютерное тестирование имеет для студентов, которые обучаются не на родном языке. Им тестирование помогает не только в освоении биологической химии, но и в совершенствовании языковой подготовки в рамках изучаемой дисциплины.

\section{References}

1. Ponomarev NL, Smirnov BM. Obrazovatelnye innovacii. Gosudarstvennaja politika i upravlenie [Educational innovations. Public policy and management]. Moskva: Academia; 2007. 208 p. (Russian). obrazovanii [Testing in modern education]. Moskva: Vysshaja shkola; 2010. 381 p. (Russian).

3. Borovikov VP. Statistica. Iskusstvo analiza dannyh na kompjutere [Statistica. The art of analyzing data on a computer]. Sankt-Peterburg: Piter; 2003. 688 p. (Russian).

4. Majorov AN. Teorija i praktika sozdanija testov dlja sistemy obrazovanija: kak vybirat, sozdavat $\mathrm{i}$ ispolzovat testy dlja celej obrazovanija [Theory and practice of creating tests for the educational system: how to choose, create and use tests for education]. Moskva: IntellektCentr; 2002. 352 p. (Rus-sian).

5. Kurbat MN, Ledneva IO, Petushok NE, Lelevich VV. Jeffektivnost ispolzovan-ija kompjuternogo testirovanija pri itogovom trehstupenchatom kontrole znanij studentov [Effektivnost' ispol'zovaniya komp'yuternogo testirovaniya pri itogovom trekhstupenchatom kontrole znanij studentov]. Vyshejshaja shkola [Higher school] 2009;1:63-65. (Russian).

6. Kurbat MN, Petushok NE, Ledneva IO, Lelevich VV. Primenenie kompjuter-nogo testirovanija dlja ocenki uchebnyh dostizhenij studentov po biologicheskoj himii [The use of computer testing to assess the academic achievements of students in biological chemis-try]. In: Tarantej VP, executive editor. TehnoObraz 2009: Tehnologii ocenki uchebnyh dosti-zhenij uchashhihsja i studentov. Materialy VII Mezhdunarodnoj nauchnoprakticheskoj konferencii; 2009 Mart 17-18; Grodno. Grodno; 2009. p. 297-301. (Russian).

7. Kurbat MN, Ledneva IO, Lelevich VV, Petushok NE. Kompjuternoe testiro-vanie kak komponent trehstupenchatogo kontrolja znanij inostrannyh uchashhihsja po biologicheskoj himii [Computer testing as a component of the three-level control of knowledge of
2. Kabanova TA, Novikov VA. Testirovanie v sovremennom 


\title{
Педагогический процесс
}

foreign students in biological chemistry]. In: Pestis VK, Duduk AA, Sviridov AV, Jurgel SI, editors. Perspektivy razvitija vysshej shkoly. Materialy II Mezhdunarodnoj nauchno-metodicheskoj konferencii; 2016 Maj 19-20; Grodno. Grodno; 2016. p. 354-357. (Russian).

\section{COMPUTER TESTING AS A METHOD FOR ESTIMATION OF ACADEMIC ACHIEVEMENTS OF STUDENTS ON BIOLOGICAL CHEMISTRY IN MEDICAL UNIVERSITIES}

Petushok N. E., Ledneva I. O., Lelevich V. V., Kurbat M. N. Educational Institution «Grodno State Medical University», Grodno, Belarus

\begin{abstract}
Background. Assessment of students' knowledge is one of the key tasks of any educational system.
The aim of the study is to identify the significance of testing in a multipurpose system of means of assessing students' knowledge.

Material and methods. Statistic analysis of the relationship of the results of computer testing, the examination score and the average annual score.

Results. A positive correlation was revealed between all pairs of the compared indicators. For students of the Faculty of General Medicine high strength of relationship was noted for the average annual score $\leftrightarrow$ examination score and testing $\leftrightarrow$ examination score. For students of the Medical Faculty for International Students, the tendencies of interdependence of the indicators are similar, the strength of relationship is less pronounced.

Conclusions. Computer testing should be used in complex with other tools of assessment of academic achievements.

Keywords: Computer testing, average annual score, examination score, correlation index.
\end{abstract}

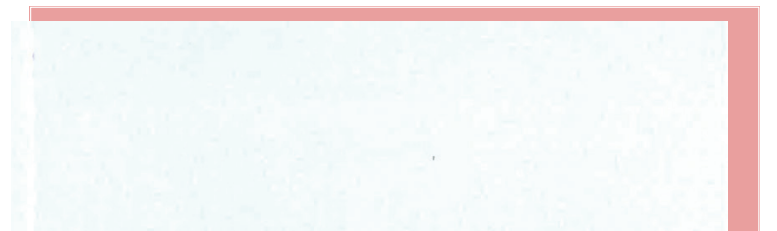

НЕОТЛОЖНАЯ НЕВРОЛОГИЯ

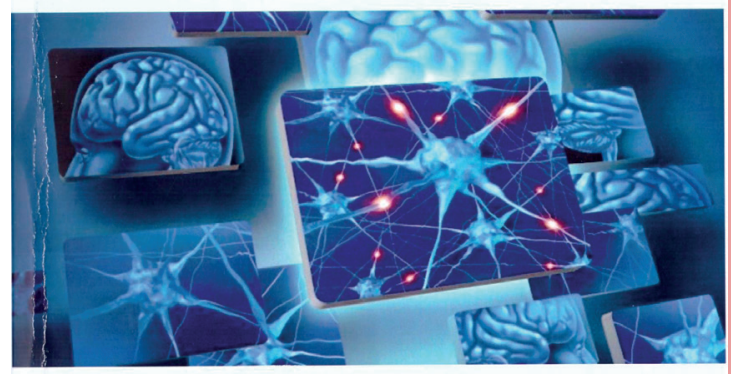

Учебно-методическое пособие
Неотложная неврология : учебно-методическое пособие для студентов учреждений высшего образования, обучающихся по специальности 1-79 0105 "Медикопсихологическое дело" : рекомендовано учебно-методическим объединением по высшему медицинскому, фармацевтическому образованию / Министерство здравоохранения Республики Беларусь, Учреждение образования "Гродненский государственный медицинский университет", Кафедра неврологии и нейрохирургии ; [Я. Я. Гордеев, Т. М. Шамова, Т. Я. Лебейко, А. И. Лебейко]. Гродно : ГрГМУ, 2017. - 179 с. - Библиогр.: с. 179. - ISBN 978-985-558-899-4.

Книга посвящена вопросам врачебной тактики при неотложных состояниях в неврологии: нарушениях мозгового кровообращения, инфекционных и инфекционно-аллергических заболеваниях нервной системы, травматических поражениях иентральной нервной системы, нервно-мышечных заболеваниях, пароксизмальных состояниях. Пособие адресовано обучающиися по специиальности 1 - 79 0105 «Медико-психологическое дело», а также может быть полезным студентам всех факультетов высших медицинских учебных заведений. 